\title{
PRESENTATION OF THE EDWARD WOOD COLLECTION TO THE
} YORK MUSEUM.

SiR,-The well-known collection of fossils formed by the late Mr. E. Wood, of Richmond, Yorkshire, has been purchased by Mr. Wm. Reed, F.G.S., of York, and by him presented to the Museum of the Yorkshire Philosophical Society, York.

The collection consists of about 10,000 specimens, and is specially rich in fossils from the Carboniferous rocks. W. K EEPING.

The Musetis, York, Jan. 17th, 1881.

Mr. Reed had previously presented his own magnificent collection of fossils to the Yorkshire Philosophical Society.

\section{MISCEIIAIVEOUS.}

A Fossil Rhinoceros in the Flesh.- The body of a large Rhinoceros was recently discovered in the Werohojanksi district, Siberia. It was found on the bank of a small tributary to the Jana (Lena?) river, and was laid bare by the action of the water. It was remarkably well preserved, the skin being unbroken and covered with long hair. Unfortunately only the skull of this rare fossil has reached St. Petersburg, and a foot is said to be at Irkutsk, while the remainder was allowed to be washed away by the river soon after it had been discovered. The investigation of the skull shows that this Rhinoceros ( $R$. Merckii) is a connecting form hetween the species now existing and the so-called Rhinoceros tichorhinus, remains of which are not unfrequently found in the Brick-earth of the Valley of the 'Thames at Ilford, and in Prussia.

THe Readers of this Magazine will be glad to learn that Mr. A. R. Wallace, the celebrated explorer, naturalist, and author, is to receive a pension of $£ 200$ a year from the Government, in recognition of his eminence in zoological science, in promoting which he has done so much good service.

We are requested by the author to print the subjoined list of Errata in Mr. H. H. Howorth's paper on "The Mammoth in Siberia," Geol. Mag. Dec. 1880, pp. $550-561$.

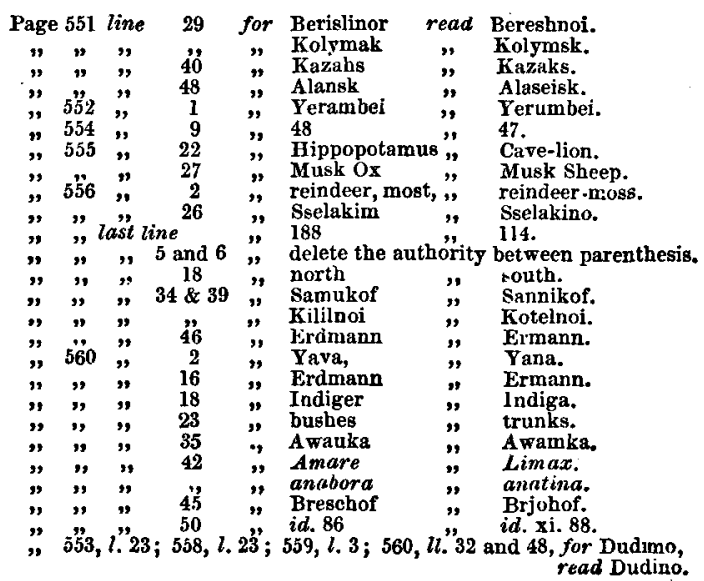

